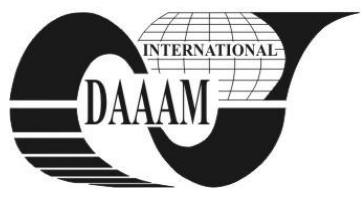

Annals of DAAAM for 2011 \& Proceedings of the 22nd International DAAAM Symposium, Volume 22, No. 1, ISSN 1726-9679 ISBN 978-3-901509-83-4, Editor B. Katalinic, Published by DAAAM International, Vienna, Austria, EU, 2011 Make Harmony between Technology and Nature, and Your Mind will Fly Free as a Bird Annals \& Proceedings of DAAAM International 2011

\title{
SUITABLE DEVICES FOR MEASURING ROUGHNESS ON OIL FILTER HOUSING
}

\section{JURJEVIC, M[arin]; BARISIC, B[ranimir]; KATALINIC, B[ranko]; KRSULJA, M[arko] \& CAR, Z[latan]}

\begin{abstract}
The main target of this paper is to find out the most suitable device for measurements of roughness of aluminum parts during the production process. Measurement and investigation are made on following devices MarSurf GD 25, PCE-1200 RT. The measurements were conducted on six pieces selected from one production cycle. Comparisons of results are presented in graphical and numerical tables and best device is selected
\end{abstract}

Key words: surface roughness, parameters, measurement device

\section{INTRODUCTION}

During the production of machine parts, great attention is given to final treatment, which is important in many areas of mechanical engineering. Moving machine parts very often generate movement in touch, where decreased roughness plays a major role. Measuring the profile of surface roughness is one of regular controls conducted in the production of machine parts. In this paper, we present measurement of surface roughness with the use three different devices and their results are compared. Measurements were made on an aluminum oil filter housing used in car engines, casting alloy ALSi9Cu3. Investigation was conducted with fallowing measurement devices: MarSurf GD 25, PCE-1200 RT .The device MarSurf GD 25 is regularly calibrated and used in factory facilities Cimos while PCE-RT1200 is a new device and has never used and should be more precise.

\section{PARAMETERS OF SURFACE ROUGHNESS}

Surface roughness parameters are defined by ISO 4287 in 1997. After that the previous definition and labeling of roughness parameters are partly altered. Central line intersects the roughness profile in such way that limits the length of the reference lr sum of squared distances $Z(X)$ of all points of the profile of this line is minimal (Gojic, 2010).

The most important parameters which determine the roughness of the technical areas are called "vertical" parameters, as measured perpendicular to the surface or middle line profiles.

$\mathrm{Ra}$ is the arithmetic mean of absolute deviation of all points of the profile from middle line within the reference length lr.

$$
R a=\frac{1}{\operatorname{lr}} \int_{0}^{l r}|Z(X)| d X \approx \frac{1}{n} \sum_{i=1}^{n}\left|Z_{i}\right|
$$

Geometric mean deviation of profile roughness $\mathrm{Rq}$ as the square root of the mean squared deviations of all points of the profile from tsthe middle line within the reference length $1 r$.

$$
R q=\sqrt{\frac{1}{l r} \int_{0}^{l r} Z^{2}(X) d X \approx \sqrt{\frac{1}{n} \sum_{i=1}^{n} Z_{i}^{2}}}
$$

$\mathrm{R}_{\mathrm{z}}$ Average Maximum Height. The average of the roughness depth values found in each of the sampling lengths comprising the evaluation length.

$$
R_{z}=\frac{1}{5} \sum_{i=1}^{5}(|y p i|+|y v i|)
$$

$\mathbf{R}_{\mathbf{3 z}}$ Base Roughness Depth. The height between the 3rd highest peak and the 3rd lowest peak in each of the divided sampling lengths.

$$
R_{3 z}=\frac{1}{n} \sum_{i=1}^{n} R_{3 z i}
$$

Rku Is a measure of the „sharpness“ of the ADC.

$$
R_{k u}=\frac{1}{R_{q}^{4}} \cdot \frac{1}{I} \int\left|z^{4}(x)\right| d x
$$

Rsk Skewness is measure of the symmetry of the Amplitude Density Curve (ADC)

$$
R_{s k}=\frac{1}{R_{q}^{3}} \cdot \frac{1}{I}\left|z^{3}(x)\right| d x
$$

$\mathbf{R}_{\max }$ Maximum Roughness Depth. The largest of the roughness depth values found in each of the sampling lengths comprising the evaluation length.

$\mathbf{W}_{\mathrm{t}}$ Waviness Height The height from the highest peak to the deepest valley on the waviness profile within the evaluation length.Sampling Length $\left(l_{\mathrm{r}}\right)$ : A length on the measured workpiece over which parameters are calculated. This is usually equal to the filter cutoff length (ISO4287).

\section{ALUMINIUM CASTING USED IN FOR ROUGHNESS MEASUREENT}

Aluminum casting is used as experimental surface to compare results and parameters of Mahr MarSurf GD 25, PCERT 1200 and Mitutoyo devices. The housing is made of aluminum alloy and is processed by the client specifications.

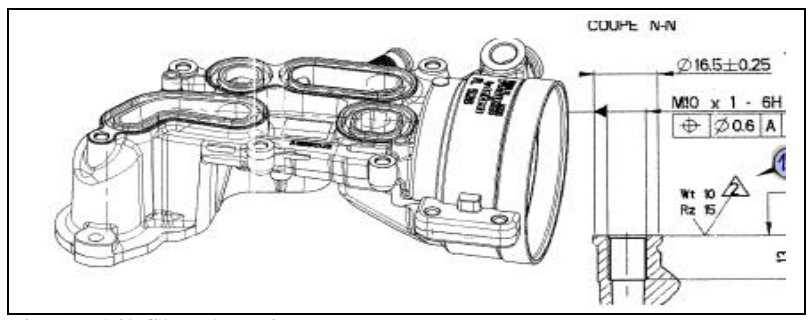

Fig. 1. Oil filter housing

\subsection{Mahr MarSurf GD (gear drive) 25 specification}

The housing, the bottom of which is in the form of a prism, is compact and robust. The GD features a motor-driven height adjustment for lowering and lifting the pick-up and for setting it to zero automatically. The motor-driven height adjustment automatically changes the total position of the pickup such that the stylus tip remains in the middle of the measuring range. (www.mahr.com). 


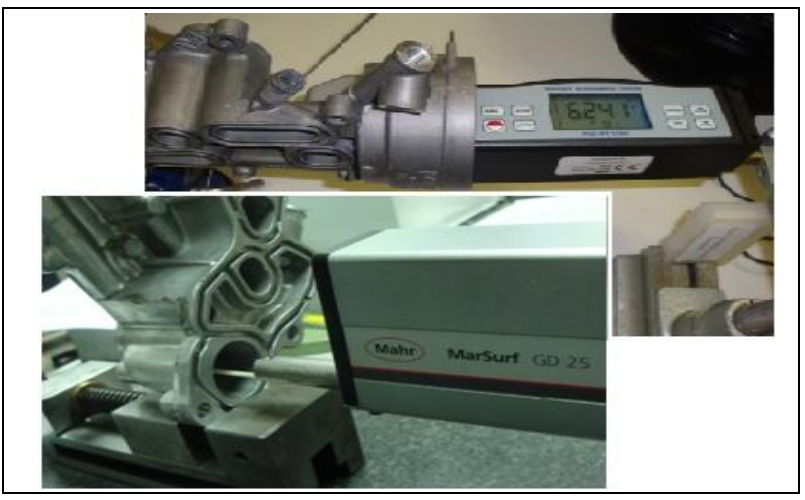

Fig. 2. Example of measuring with Mahr MarSurf GD 25 and PCE-RT 1200 devices

\subsection{PCE-RT 1200 specifications}

The PCE-RT 1200 meets almost all standards for the detection of roughness. It can test the surface of many different surfaces. The device comes with a mechanism to level off surface irregularities. It's especially useful for a series of measurements, such as testing the parts shipments or to check internal quality. Specifications are detects $\mathrm{Ra}, \mathrm{Rz}, \mathrm{Rq}, \mathrm{Rt}$. Measures the inside of spaces from $6 \mathrm{~mm}$ of diameter and with a depth of $15 \mathrm{~mm}$, easy to use menu, large LCD with backlight, memory for 7 series of measurements, RS-232 interface, rechargeable ion-lithium battery, ISO calibration certificate.

\section{MEASURING RESULTS}

The results of measurements of roughness using two measuring devices performed on six equal castings presenting following results.

1. Sealing surface on filter housing (base 104). Maximum Rmax parameter allowed is $8 \mu \mathrm{m}$

2 Sealing surface on filter housing (base 104). Maximum Ra parameter allowed $1,6 \mu \mathrm{m}$

3. Surface for bolts and nuts (base 184). Maximum Wt parameter allowed $10 \mu \mathrm{m}$

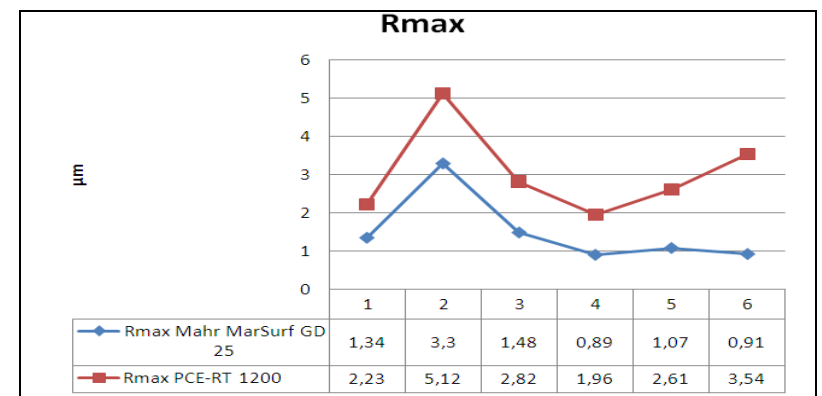

Fig. 3. Comparison of parameters Rmax (MarSurf GD 25, PCERT 1200)

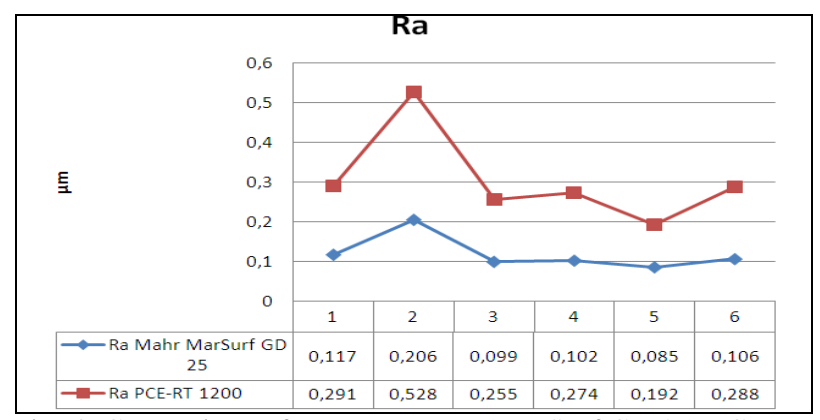

Fig. 4. Comparison of parameters Ra (MarSurf GD 25, PCE-RT 1200)

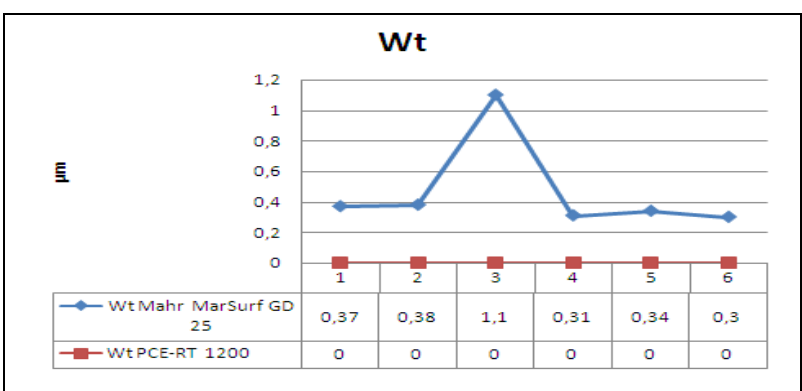

Fig. 5. Comparison of parameters Wt (MarSurf GD 25, PCERT 1200)

\section{CONCLUSION}

Based on analysis of measurements results and measurement process we came to following conclusions.

That PCE-RT 1200 device shows higher values than Mahr MarSurf GD 25. MarSurf is calibrated and used in factory conditions and PCE-RT 1200 is used in laboratory condition. The laboratory used equipment are taken as more precise and a new calibration of factory measuring device is recommended, and more frequent calibration period is also recommended. PCE-RT 1200 device cannot measure with Wt parameters, which is shown at one of the enclosed figures, however it is a much cheaper device and more robust, it has less capabilities but there is also less possibility for error. Mahr MarSurf GD 25 device can reach much deeper and heavy accessible area than PCE-RT 1200. PCE-RT 1200 has proven to be good for the measurement of large flat surfaces while the Mahr MarSurf GD 25 is much better for detailed castings. Comparison of prices and capability is give in table 1 .

\begin{tabular}{|c|c|c|}
\hline & MarSurfGD25 & PCE-RT1200 \\
\hline Drive unit & yes & No \\
\hline Price & $£ 10710^{*}$ & $£ 902.85$ \\
\hline Parameters & All defined byISO & Ra, Rz, Rq, Rt \\
\hline Waviness parameters & All defined byISO & Not available \\
\hline
\end{tabular}

*-with driving unit

Tab. 1. Comparation of specifications of measurement devices

\section{ACKNOWLEDGEMENTS}

The authors would like to acknowledge the support provided by the National CEEPUS Office of Croatia and National CEEPUS Office Austria, which helped the research through mobility in the frame of the CEEPUS II HR 0108 project.

\section{REFERENCES}

Gojic, M. (2010). Surface treatment of materials, University of Zagreb, ISBN 978-953-7082-09-3, Zagreb

***(1997) ISO4287 - International Organization for Standardization Geneva, Switzerland, Accessed on:201107-13

***(2007) www.mahr.com - PC-based stationary surface measuring stations, Mahr GmbH Gottingen, Germany, Accessed on: 2011-07-14

***(2007)www.fsb.hr/elemstroj/pdf/design/2007/hrapavost_teh nick ih_povrsina.pdf -Tehnical University of Zagreb, Accessed on: 2011-06-28

***(2010) www. tesabs.ch -TESA SA, Innovation in measuring equipment since 1941, Hexagon Metrology, Switzerland, Accessed on: 2011-06-28 